Bangladesh J. Pl. Breed. Genet, 25(1): 31-39, 2012

\title{
GENETIC DIVERSITY ANALYSIS IN RICE (Oryza sativa L.)
}

\author{
S. P. Chakma ${ }^{1}$, H. Huq ${ }^{2}$, F. Mahmud and A. Husna ${ }^{3}$ \\ ${ }^{3}$ Department of Genetics and Plant Breeding, Sher-e-Bangla Agricultural \\ University, Sher-e-Bangla Nagar, Dhaka-1207
}

\begin{abstract}
The experiment was conducted under the agro-ecological zone of Modhupur Tract (AEZ-28) to determine the genetic diversity among 39 rice genotypes, collected from Bangladesh Rice Research Institute, Lal Teer Seed Ltd. and Chittagong Hill Tracts. The genotypes were grouped into six clusters based on Mahalanobis's D ${ }^{2}$ statistics and Canonical Variate Analysis. Cluster I consisted with the highest number of (11) genotypes from different origin, whereas cluster IV consisted with the lowest number of (3) genotypes. Cluster III consisted of BRRI dhan 28, BRRI dhan 45, Gold, Tia, Dowel and Moyna showed maximum mean yield. Maximum inter cluster distance was recorded between cluster II and cluster III. The highest inter genotypic distance was observed between Tharak dhan and BRRI dhan 45. Cluster III had the highest mean values for grain yield, harvest index, 1000-grain weight and number of effective tillers per hill and cluster V for number of primary branches per panicle and cluster VI for number of filled grains per panicle that had significant positive correlation with grain yield. Number of unfilled grains per panicle, 1000-grain weight and grain yield showed maximum contribution towards genetic divergence. The genotypes from these clusters with desirable characters may be used as potential donor for future hybridization program to develop high yielders.
\end{abstract}

Key words: Rice (Oryza sativa L.), genetic diversity, $\mathrm{D}^{2}$ analysis, canonical variate analysis.

\section{INRODUCTION}

Rice (Oryza sativa L.) is a self pollinated cereal crop belonging to the family Gramineae (synonym-Poaceae) under the order Cyperales. It is the staple food in Bangladesh, and grown in a wide range of environments ranging from the hilly areas like Chittagong Hill Tracts, Sylhet and Garo Hills, with little moisture, to situations where the water table is 3-4 m deep (Alim, 1982). Bangladesh has a good source of indigenous rice cultivars with two million hectares coverage, while the HYV and hybrids occupy eight million hectares and one million hectares respectively (Talukder, 2011). Knowledge of genetic diversity among existing cultivars of any crop is essential for long term success of breeding program and maximizes the exploitation of the genetic resources (Belaj et al., 2002). Hybridization is one of the major tools for the improvement of a crop that needs the analysis of genetic diversity for the selection of parents (Singh, 1983). Moreover, evaluation of genetic diversity is important for the source genes of particular traits within the available germplasm (Roy and Panwar, 1993).

\footnotetext{
${ }^{1}$ Agricultural Research Station, Bangladesh Agricultural Research Institute, Raikhali, Rangamati; ${ }^{2}$ Department of Biotechnology, Sher-e-Bangla Agricultural, University, Sher-eBangla Nagar, Dhaka 1207; ${ }^{3}$ Bahar Agriculture College, Kustia
} 
Genetic diversity assessment between and within groups or clusters is very important for the proper selection of parents for the better search of heterosis (Murty and Arunachalam, 1966). Multivariate analysis with $\mathrm{D}^{2}$ technique measures the amount of genetic diversity in a given population in respect of several characters and assesses relative contribution of different components to the total divergence (Zahan et al., 2008). This study was undertaken to determine the genetic diversity in rice for the maximum utilization of the genetic resources and proper selection of donor parents.

\section{MATERIALS AND METHODS}

The experiment was conducted at the experimental field of Sher-e-Bangla Agricultural University (SAU), Dhaka 1207, Bangladesh, in irrigated condition during January to June in 2011. The experimental materials comprised of 39 rice genotypes collected from Genetic Resources and Seed (GRS) Division of Bangladesh Rice Research Institute (BRRI), Lal Teer Seed Ltd. (LTSL) and Chittagong Hill Tracts (CHT) (Table 1). The experiment was laid out in a Randomized Complete Block Design (RCBD) with three replications. Row and plant spacing were maintained $25 \times 20 \mathrm{~cm}$ and two seedlings per hill were transplanted. Experimental plots were fertilized with the recommended doses of 140-20-60-20-4 kg/ha N-P-K-S-Zn (BRRI, 2011). First split of nitrogenous fertilizer and full portion of all other fertilizers were added to the main land during final ploughing. The second and third splits of nitrogenous fertilizer were applied at 4-5 tillering stage and 5-7 days before of panicle initiation, respectively.

Table 1. List of thirty nine rice genotypes along with their sources

\begin{tabular}{cccccc}
\hline Accession no. & Genotypes & Source & Accession no. & Genotypes & Source \\
\hline G1 & Sada Kabarak & CHT & G21 & BR-24 (Rahmat) & GRS, BRRI \\
G2 & Kala kabarak & CHT & G22 & BR-25 (Naya Pajam) & GRS, BRRI \\
G3 & Kamrang dhan & CHT & G23 & BR-26 (Shraboni) & GRS, BRRI \\
G4 & Badeye dhan & CHT & G24 & BRRI dhan-27 & GRS, BRRI \\
G5 & Sada gelon & CHT & G25 & BRRI dhan-28 & GRS, BRRI \\
G6 & Jumma Bini (longer grain) & CHT & G26 & BRRI dhan-29 & GRS, BRRI \\
G7 & Jumma Bini (shorter grain) & CHT & G27 & BRRI dhan-30 & GRS, BRRI \\
G8 & Kabarak dhan & CHT & G28 & BRRI dhan-31 & GRS, BRRI \\
G9 & Ameiye dhan & CHT & G29 & BRRI dhan-32 & GRS, BRRI \\
G10 & Tharak dhan & CHT & G30 & BRRI dhan-33 & GRS, BRRI \\
G11 & Paijam (Indian) & CHT & G31 & BRRI dhan-36 & GRS, BRRI \\
G12 & Jumma Kabarak & CHT & G32 & BRRI dhan-39 & GRS, BRRI \\
G13 & Gold (China) & LTSL & G33 & BRRI dhan-40 & GRS, BRRI \\
G14 & Tia (China) & LTSL & G34 & BRRI dhan-42 & GRS, BRRI \\
G15 & Dowel (China) & LTSL & G35 & BRRI dhan-44 & GRS, BRRI \\
G16 & Moyna (China) & LTSL & G36 & BRRI dhan-45 & GRS, BRRI \\
G17 & BR-3 (Biplob) & GRS, BRRI & G37 & BRRI dhan-48 & GRS, BRRI \\
G18 & BR-10 (Pragati) & GRS, BRRI & G38 & BRRI dhan-49 & GRS, BRRI \\
G19 & BR-11 (Mukta) & GRS, BRRI & G39 & BRRI dhan-50 & GRS, BRRI \\
G20 & BR-22 (Kiran) & GRS, BRRI & & \\
\hline
\end{tabular}

Data were collected on 12 agronomic characters viz. plant height at maturity $(\mathrm{cm})$, number of effective tillers per hill, length of panicles $(\mathrm{cm})$, days to $80 \%$ flowering (days after sowing), number of primary branches per panicle, number of secondary branches per panicle, days to maturity (days after sowing), number of unfilled grains per panicle, number of filled grains per panicle, 1000-grain weight $(\mathrm{g})$, harvest index and grain yield per hill $(\mathrm{g})$. Data were taken from 10 hills of each genotype. All the analyses in respect of twelve different morphological traits of 39 rice genotypes were analyzed by multivariate analyses using the GENSTAT 5-13 software program. The genotypes were grouped into clusters based on Mahalanobis's $\mathrm{D}^{2}$ statistics and canonical variate analysis. 


\section{RESULTS AND DISCUSSION}

\section{Principal component analysis}

The principal component analysis (PCA) provided eigen values and percent of variation for 12 principal component axes in 39 rice genotypes (Table 2). The results showed that only the first three principal components jointly accounted for $65.79 \%$ of the total variation among the genotypes, while these three exhibited eigen values above unity. The first two principal axes accounted for $52.76 \%$ of the total variation among the 12 component axes of the total genotypes (Table 2). Principal component analysis was also reported by Anandan et al. (2011) and Latif et al. (2011) in rice.

Table 2. Eigen values and percent of variation for 12 principal component axes in 39 rice genotypes

\begin{tabular}{cccc}
\hline $\begin{array}{c}\text { Component } \\
\text { axes }\end{array}$ & Eigen values & Percent variation & Cumulative Percent variation \\
\hline 1 & 3.77 & 31.44 & 31.44 \\
2 & 2.56 & 21.32 & 52.76 \\
3 & 1.56 & 13.03 & 65.79 \\
4 & 0.95 & 7.94 & 73.73 \\
5 & 0.87 & 7.28 & 81.01 \\
6 & 0.74 & 6.17 & 87.18 \\
7 & 0.59 & 4.89 & 92.07 \\
8 & 0.31 & 2.62 & 94.69 \\
9 & 0.30 & 2.47 & 97.16 \\
10 & 0.15 & 1.28 & 98.44 \\
11 & 0.11 & 0.93 & 99.37 \\
12 & 0.08 & 0.63 & 100.00 \\
\hline
\end{tabular}

\section{Construction of scattered diagram}

A two dimensional scatter diagram $\left(\mathrm{Z}_{1}-\mathrm{Z}_{2}\right)$ was constructed using component 1 as $\mathrm{X}$-axis and component 2 as $\mathrm{Y}$-axis based on the values of principal component scores 1 and 2 obtained from the principal component analysis. The genotypes were grouped into six clusters indicating the presence of considerable genetic diversity among genotypes (Figure 1). BRRI dhan 45 (G 36) was distantly located from Tharak dhan (G 10).

\section{Principal coordinate analysis}

Inter genotypic distance was obtained from principal coordinate analysis on auxiliary of principal component analysis for all possible combinations between pairs of genotypes (Table 3). Maximum inter genotypic distance was found between Tharak and BRRI dhan 45 (237.41) followed by Jumma Bini (shorter grain) and BRRI dhan 45 (224.81), Badeye and BRRI dhan 45 (219.43), while minimum inter genotypic distance was found between Paijam (India) and BRRI dhan 50 (1.23) followed by Kabarak and BR 25 (2.24), Kamrang and Paijam (India) (2.43). The presence of differences between the highest and the lowest inter genotypic distances indicated the presence of variability among 39 rice genotypes. Similar results also obtained by Latif et al. (2011) in rice.

\section{Canonical variate analysis}

The canonical variate analysis, complementary to Mahalanobis's $\mathrm{D}^{2}$ statistics, was carried out to obtain the cluster distances (Mahalanobis's $\mathrm{D}^{2}$ values) that indicated 
the index of genetic diversity among them. There was wider genetic diversity among the genotypes of different cluster as inter cluster distances were larger than intra cluster distances (Table 4). Similar results were also suggested by Anandan et al. (2011) and Latif et al. (2011) in rice.

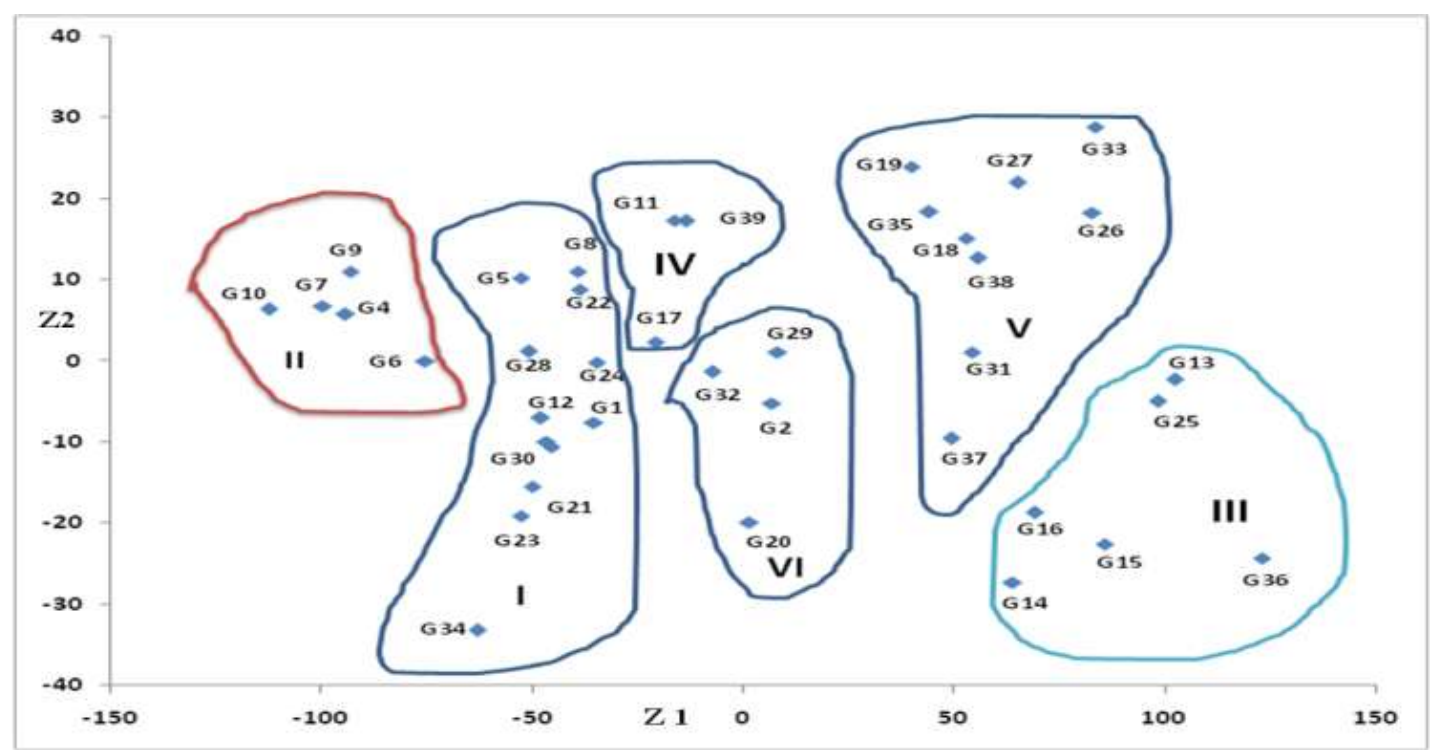

Figure 1. Scatter diagram of 39 rice genotypes based on PCA scores superimposed with clustering from $\mathrm{D}^{2}$ analysis

Table3. Ten highest and ten lowest inter genotypic distance among 39 rice genotypes

\begin{tabular}{|c|c|c|c|c|c|c|c|}
\hline \multicolumn{4}{|c|}{ Highest distance } & \multicolumn{4}{|c|}{ Lowest distance } \\
\hline Sl. & \multicolumn{2}{|c|}{ Genotypes } & \multirow{2}{*}{$\begin{array}{c}\text { Distance } \\
237.41\end{array}$} & \multirow{2}{*}{$\begin{array}{l}\text { Sl. } \\
\text { No. }\end{array}$} & \multicolumn{2}{|c|}{ Genotype } & \multirow{2}{*}{$\begin{array}{c}\text { Distance } \\
1.23\end{array}$} \\
\hline 01 & Tharak & BRRI dhan 45 & & & Paijam (India) & BRRI dhan 50 & \\
\hline 02 & $\begin{array}{l}\text { Jumma Bini } \\
\text { (Shorter grain) }\end{array}$ & BRRI dhan 45 & 224.81 & 02 & Kabarak & BR 25 & 2.24 \\
\hline 03 & Badeye & BRRI dhan 45 & 219.43 & 03 & Kamrang & Paijam (India) & 2.43 \\
\hline 04 & Ameiye & BRRI dhan 45 & 218.95 & 04 & Jumma Kabarak & BRRI dhan 33 & 3.23 \\
\hline 05 & Tharak & Sada Kabarak & 214.95 & 05 & BR 10 & BRRI dhan 49 & 3.75 \\
\hline 06 & Tharak & BRRI dhan 28 & 211.05 & 06 & Jumma Kabarak & BRRI dhan 50 & 4.25 \\
\hline 07 & $\begin{array}{c}\text { Jumma Bini } \\
\text { (Shorter grain) }\end{array}$ & Sada Kabarak & 202.22 & 07 & BR 24 & BRRI dhan 26 & 4.54 \\
\hline 08 & Tharak & Dowel & 200.21 & 08 & Sada Kabarak & BRRI dhan 28 & 4.87 \\
\hline 09 & $\begin{array}{l}\text { Jumma Bini (longer } \\
\text { grain) }\end{array}$ & BRRI dhan 45 & 199.85 & 09 & Badeye & $\begin{array}{r}\text { Jumma Bini } \\
\text { (Shorter grain) }\end{array}$ & 5.39 \\
\hline 10 & $\begin{array}{c}\text { Jumma Bini } \\
\text { (shorter grain) }\end{array}$ & BRRI dhan 28 & 198.33 & 10 & Badeye & Ameiye & 5.45 \\
\hline
\end{tabular}

Maximum inter cluster distance was observed between clusters II and III (15.84) indicating the highest diversity among the genotypes of these clusters followed by clusters II and V (11.91), clusters I and III (11.68), and clusters III and IV (10.99), while the minimum was between clusters I and VI (3.61) indicating the lowest diversity among the genotypes of these clusters followed by clusters I and II (4.83), clusters IV and VI (5.50), and clusters V and VI (5.69). The more inter and intra cluster distances, the more variability among the genotypes between and within the cluster, respectively and vice versa. The cluster means of 12 characters of 39 rice genotypes are presented in Table 6 . 
There was also observed the existence of differences for almost all of the characters. Genotypes of distantly located clusters were suggested to use in hybridization programs for obtaining a wide spectrum of variation among the segregates as suggested by Yadav et al. (2011), Vennila et al. (2011) and Latif et al. (2011).

Table 4. Intra cluster distances (Bold) and inter cluster distances $\left(D^{2}\right)$ for 39 rice genotypes

\begin{tabular}{l|c|c|c|c|c|c}
\hline Cluster & I & II & III & IV & V & VI \\
\hline I & $\mathbf{0 . 0 2}$ & 4.83 & 11.68 & 5.95 & 8.66 & 3.61 \\
II & & $\mathbf{0 . 1 4}$ & 15.84 & 7.97 & 11.91 & 7.95 \\
III & & & $\mathbf{0 . 0 7}$ & 10.99 & 6.38 & 8.44 \\
IV & & & & $\mathbf{0 . 5 9}$ & 6.97 & 5.50 \\
V & & & & & $\mathbf{0 . 0 3}$ & 5.69 \\
VI & & & & & & $\mathbf{0 . 1 4}$ \\
\hline
\end{tabular}

\section{Non-hierarchical clustering}

Thirty nine rice genotypes were grouped into six different clusters based on nonhierarchical clustering using co-variance matrix. Distributions of genotypes into different clusters are presented in Table 5. Cluster I contained maximum number of genotypes (11) while cluster V, cluster III, cluster II/cluster VI and cluster IV contained 9, 6, 5 and 3 genotypes, respectively (Table 5). The genotypes collected from Chittagong Hill Tracts those are mostly cultivated in Jhum (shifting cultivation) were distributed in all clusters except in cluster $\mathrm{V}$ as days to flowring was maximum (113.58 DAS) in this cluster (Table 6). Whereas, the genotypes collected from BRRI were distributed in all clusters except in cluster II as plant height was maximum $(114.10 \mathrm{~cm})$ in this cluster (Table 6). All the genotypes collected from Lal Teer Seed Ltd. along with BRRI dhan 28 and BRRI dhan 45 were grouped in cluster III that were resulted maximum yield in this study (Table 6). The clustering pattern suggests that the genotypes collected from same locations (hilly area) can also be grouped into different clusters. This showed that geographic distribution was not related to genetic diversity of these materials. Similar results were also reported by Yadav et al. (2011) and Anandan et al. (2011) in rice.

Table 5. Distribution of 39 rice genotypes in different clusters

\begin{tabular}{c|cll}
\hline Cluster & Member & Genotypes \\
\hline I & 11 & $\begin{array}{l}\text { Sada Kabarak, Sada Gelon, Kabarak, Jumma Kabarak, BR-24, BR-25, } \\
\text { BR-26, BRRI dhan 27, BRRI dhan 31, BRRI dhan 33, BRRI dhan 42 } \\
\text { Badeye, Jumma Bini (longer grain), Jumma Bini (shorter grain), } \\
\text { Ameiye, Tharak }\end{array}$ \\
II & 5 & 6 & $\begin{array}{l}\text { Gold, Tia, Dowel, Moyna, BRRI dhan 28, BRRI dhan 45 } \\
\text { III }\end{array}$ \\
IV & 3 & $\begin{array}{l}\text { Paijam (Indian), BR-3, BRRI dhan 50 } \\
\text { BR 10, BR 11, BRRI dhan 29, BRRI dhan 30, BRRI dhan 36, BRRI } \\
\text { dhan 40, BRRI dhan 44, BRRI dhan 48, BRRI dhan 49 } \\
\text { Kala Kabarak, Kamrang, BR 22, BRRI dhan 32, BRRI dhan 39 }\end{array}$ \\
VI & 5 &
\end{tabular}

\section{Characterization of individual cluster}

Intra cluster mean vales of 12 different characters of 39 rice genotypes are presented in Table 6. Maximum intra cluster mean for plant height was found in cluster II (114.10) followed by cluster I (110.41) and cluster VI (106.88), whereas the lowest intra cluster mean was found in cluster IV (81.51) followed by cluster V (92.44) and cluster III (93.42). The maximum intra cluster mean for number of effective tillers per 
hill was observed in cluster III (11.57) followed by cluster V (11.44) and cluster IV (10.98), whereas the lowest was found in cluster VI (10.36) followed by cluster II (10.50) and cluster I (10.64). The maximum intra cluster mean for panicle length was shown in cluster V (26.72) followed by cluster II (25.82) and cluster VI (25.32), whereas the lowest was in cluster III (23.77) followed by cluster I (25.06) and cluster IV (25.26). The maximum intra cluster mean for days to $80 \%$ flowering was observed in cluster $\mathrm{V}$ (113.58) followed by cluster IV (110.78) and cluster II (109.47), whereas the minimum was observed in cluster III (91.78) followed by cluster I (102.88) and cluster VI (104.60). The highest intra cluster mean for number of primary branches per panicle was observed in cluster V (11.71) followed by cluster II (10.62) and cluster VI (10.31), whereas the minimum was observed in cluster III (9.03) followed by cluster IV (9.52) and cluster I (10.18). The maximum intra cluster mean for number of secondary branches per panicle was found in cluster II (29.80) followed by cluster I (26.79) and cluster VI (25.09), whereas the minimum was in cluster III (20.24) followed by cluster IV (24.26) and cluster V (25.06). The highest intra cluster mean for number of unfilled grains per panicle was observed in cluster IV (30.82) followed by cluster II (27.31) and cluster I (22.17), whereas the minimum was in cluster III (17.39) followed by cluster VI (18.02) and cluster V (21.62). The maximum intra cluster mean was found in cluster VI (142.22) followed by cluster V (141.80) and cluster III (135.22), whereas the minimum was found in cluster IV (120.44) followed by cluster II (126.96) and cluster I (134.39). The maximum intra cluster mean for 1000-grains weight was observed in cluster III (27.69) followed by cluster VI (25.87) and cluster V (24.77), whereas the lowest was in cluster II (19.73) followed by cluster IV (22.89) and cluster I (24.40). The maximum intra cluster mean for days to maturity was shown in cluster II (143.07) followed by cluster V (142.19) and cluster IV (140.67), whereas the minimum was in cluster III (119.50) followed by cluster I (129.82) and cluster VI (130.13). The highest intra cluster mean for harvest index was observed in cluster III $(0.55)$ followed by cluster V $(0.53)$ and cluster IV $(0.51)$, whereas the lowest was observed in cluster II $(0.35)$ followed by cluster I (0.44) and cluster VI (0.46). The maximum intra cluster mean for grain yield per hill was observed in cluster III (33.27) followed by cluster V (30.17) and cluster VI (24.23), whereas the minimum was in cluster II (15.03) followed by cluster I (19.73) and cluster IV (21.52). The highest intra cluster mean for respected characters were shown in bold and the lowest intra cluster mean were shown in italic in Table 6 . The cluster III had ranked first for the maximum times (4 times) followed by clusters II and V (3 times each), cluster IV and VI (once each) for maximum values, whereas cluster I had no first ranking for maximum value. However, the cluster III again had ranked in first for the maximum times (6 times) followed by cluster II (3 times), cluster IV (2 times) and cluster VI (once) for minimum values, whereas there was no first ranking of cluster I and cluster $\mathrm{V}$ for minimum value. Therefore, most of the important traits present in genotypes under cluster III.

\section{Contribution of characters towards divergence}

The relative contributions of twelve different characters of thirty nine rice genotypes towards the total divergence are presented in Table 7 . The result of the canonical variate analysis revealed that number of unfilled grains per panicle, 1000-grain weight and grain yield per hill had positive values in both the vectors, whereas number of effective tillers per hill, days to $80 \%$ flowering, number of primary branches per panicle, number of filled grains per panicle and days to maturity had negative values. The positive values in both the vectors revealed the most important whereas the negative values in both the vectors indicated the least important of these characters towards the 
divergence among thirty nine rice genotypes. In the vector $1\left(Z_{l}\right)$, the all other characters, excluding those were showing positive values in both vectors, showed negative values indicating that these characters showed less importance towards the genetic divergence. In the vector $2\left(Z_{2}\right)$, the other important characters towards the genetic divergence were plant height, panicle length, number of secondary branches per panicle and harvest index. Therefore, importance should be given on number of unfilled grains per panicle, 1000-grain weight and grain yield per hill. Similar results were also shown by Alam et al. (2006) in barley.

Table 6. Intra cluster mean values (the highest with bold and the lowest with italic bold) of 12 different characters of 39 genotypes

\begin{tabular}{l|c|c|c|ccc}
\hline \multicolumn{1}{c|}{ Characters } & I & II & III & IV & V & VI \\
\hline Plant height (cm) & 110.41 & $\mathbf{1 1 4 . 1 0}$ & 93.42 & $\mathbf{8 1 . 5 1}$ & 92.44 & 106.88 \\
Effective tillers per hill (no.) & 10.64 & 10.50 & $\mathbf{1 1 . 5 7}$ & 10.98 & 11.44 & $\mathbf{1 0 . 3 6}$ \\
Panicle length (cm) & 25.06 & 25.82 & $\mathbf{2 3 . 7 7}$ & 25.26 & $\mathbf{2 6 . 7 2}$ & 25.32 \\
Days to 80\% flowering (DAS*) & 102.88 & 109.47 & $\mathbf{9 1 . 7 8}$ & 110.78 & $\mathbf{1 1 3 . 5 8}$ & 104.60 \\
Primary branches per panicle & 10.18 & 10.62 & $\mathbf{9 . 0 3}$ & 9.52 & $\mathbf{1 1 . 7 1}$ & 10.31 \\
Secondary branches per panicle & 26.79 & $\mathbf{2 9 . 8 0}$ & $\mathbf{2 0 . 2 4}$ & 24.26 & 25.06 & 25.09 \\
Days to maturity (DAS ) & 129.82 & $\mathbf{1 4 3 . 0 7}$ & $\mathbf{1 1 9 . 5 0}$ & 140.67 & 142.19 & 130.13 \\
Unfilled grains per panicle (no.) & 22.17 & 27.31 & $\mathbf{1 7 . 3 9}$ & $\mathbf{3 0 . 8 2}$ & 21.62 & 18.02 \\
Filled grains per panicle (no.) & 134.39 & 126.96 & 135.22 & $\mathbf{1 2 0 . 4 4}$ & 141.80 & $\mathbf{1 4 2 . 2 2}$ \\
1000 grains weight (g) & 24.40 & $\mathbf{1 9 . 7 3}$ & $\mathbf{2 7 . 6 9}$ & 22.89 & 24.77 & 25.87 \\
Harvest index & 0.44 & $\mathbf{0 . 3 5}$ & $\mathbf{0 . 5 5}$ & 0.51 & 0.53 & 0.46 \\
Grain yield per hill (g) & 19.73 & $\mathbf{1 5 . 0 3}$ & $\mathbf{3 3 . 2 7}$ & 21.52 & 30.17 & 24.23 \\
\hline
\end{tabular}

*DAS=Days after sowing

Table 7. Relative contributions of the twelve characters of 39 rice genotypes to the total divergence

\begin{tabular}{lcc}
\hline Characters & Vector-1 & Vector-2 \\
\hline Plant height (cm) & -0.0297 & 0.1247 \\
Tillers per hill (no.) & -0.1531 & -0.0932 \\
Days to 80\% flowering & -0.0003 & -0.0363 \\
Panicle length (cm) & -0.0069 & 0.1609 \\
Primary branches per panicle (no.) & -0.2114 & -0.6256 \\
Secondary branches per panicle (no.) & -0.0103 & 0.0717 \\
Unfilled grains per panicle (no.) & 0.0498 & 0.0327 \\
Filled grains per panicle (no.) & -0.0341 & -0.1004 \\
1000-grain weight (g) & 0.0363 & 0.1541 \\
Days to maturity & -0.0150 & -0.0185 \\
Harvest index & -4.4883 & 1.3369 \\
Grain yield per hill (g) & 0.0823 & 0.0089 \\
\hline
\end{tabular}

\section{Selection of characters for future improvement}

The parents for hybridization program should be selected based on the magnitude of genetic distance, contribution of different characters towards the total divergence and magnitude of cluster means for different characters performance having maximum heterosis. A higher heterosis could be produced from the crosses between genetically distant parents (Falconer, 1960). Therefore crosses between the genotypes of clusters II and III, II and V, I and III, III and IV would give high manifestation of heterosis as well as wide spectrum of genetic variation in $\mathrm{F}_{2}$ generation. Genotypes included in cluster III 
was important for number of effective tillers per hill, earliness, number of unfilled grains per panicle, 1000-grain weight, harvest index and grain yield per hill. The genotypes of cluster VI were important for number of filled grains per panicle, cluster II was important for dwarfness and number of secondary branches. The most distantly genotypes were between cluster II and cluster III. The most important cluster was cluster III (Table 6). The important characters reported by some researchers were plant height, panicle length, number of unfilled grains per panicle, 1000-grain weight (Latif et al., 2011 and Sabesan et al., 2009), grain yield, number of effective tillers (Baradhan and Thangavel, 2011), harvest index (Ahmed et al., 2010), days to maturity (Kanwal et al., 1983) and number of secondary branches per panicle (Sinha et al., 1991). The most important characters contributing towards the divergence were number of unfilled grains per panicle, 1000-grain weight and grain yield per hill.

\section{REFERENCES}

Ahmed, M. S., K. Akter, M. Khalequzzaman, E. S. M. H. Rashid and M. K. Bashar. 2010. Diversity analysis in boro rice (Oryza sativa L.) accessions. Bangladesh J. Agric. Res. 35(1): 29-36.

Alam, A. K. M., N. Naher and M. Begum. 2006. Genetic divergence for some quantitative characters in hull-less barley. Bangladesh J. Agric. Res. 31: 347-351.

Alim, A. 1982. Bangladesh Rice. pp: 35-39.

Anandan, A., R. Eswaran and M. Prakash. 2011. Diversity in rice genotypes under salt affected soil based on multivariate analysis. Pertanika J. Trop. Agric. Sci. 34(1): 3340.

Baradhan, G. and P. Thangavel. 2011. D ${ }^{2}$ analysis in rice (Oryza sativa L.). Pl. Arch. 11(1): 373-375.

Belaj, A., Z. Satovic, L. Rallo and I. Trujillo. 2002. Genetic diversity and relationship in olive germplasm collection as determined by RAPD. Theor. Appl. Genet. 105(4): 638644.

BRRI, 2011. Adhunik Dhaner Chas. Bangladesh Rice Research Institute. Gazipur 1701, Bangladesh. pp. 26.

Falconer, D. S. 1960. Introduction to Quantiatative Genetics. The Ronald Press, New York.

Kanwal, K. S., R. M. Singh, J. Singh and R. B. Singh. 1983. Divergence gene pools in rice improvement. Theor. Appl. Genet. 65: 263-267.

Latif, M. A., M. M. Rahman, M. S. Kabir, M. A. Ali, M. T. Islam and M. Y. Rafii. 2011. Genetic diversity analyzed by quantitative traits among rice (Oryza sativa L.) genotypes resistant to blast disease. African J. Micro. Res. 5(25): 4483-4391.

Murty, B. R. and V. Arunachalam. 1966. The nature of genetic diversity in relation to breeding system in crop plants. Indian J. Genet. 26: 188-198.

Roy, A. and D. V. S. Panwar. 1993. Genetic divergence in rice. Oryza, 30: 197-201.

Sabesan, T., K. Saravanak and A. Anandan. 2009. Genetic divergence analysis for certain yield and quality traits in rice (Oryza sativa L.) grown in irrigated saline low land of Annamalinagar, South India. J. Central European Agric. 10: 405-410.

Singh, P. 1983. Studies on genetic variability and diversity of rice. Madras Agric. J. 70(7): 436-440.

Sinha, P. K., V. S. Chauhan, K. Prasad and J. S. Chauhan. 1991. Genetic divergence in indigenous upland rice varieties. Indian J. Genet. 51(1): 47-50.

Talukder, M. M. H. 2011. Governance crisis in production and distribution of hybrid seeds and its impact on market behavior and trust deficit among farmers of Bangladesh. Proceedings of the SAARC Seed Congress \& Fair, Dhaka, Bangladesh. pp: 48-57.

Vennila, S., Y. Anbuselvam and K. Palaniraja. 2011. Genetic divergence analysis using yield and quality traits in rice (Oryza sativa L.). Int. J. Recent Scientific Res. 2(7): 237-239. 
Yadav, V. K., Y. Singh, S. K. Soni and A. K. Yadav. 2011. Genetic divergence analysis in salt tolerance rice (Oryza sativa L.) genotypes. Pl. Arch. 11(2): 593-595.

Zahan, M. I., M. S. R. Bhuiyan and M. S. Hossain. 2008. Genetic divergence in Oleiferous Brassica species. J. Sher-e-Bangla Agric. Univ. 2(1): 1-6. 